\title{
Sexual Dysfunction among Males with Opiate Dependence Undergoing Methadone Maintenance Therapy (MMT)
}

\author{
Mohammad Bagher Saberi Zafarghandi, ${ }^{1}$ Maryam Mousavi Nik, ${ }^{2}$ Behrooz Birashk,, ${ }^{3,}$ Ali Assari, ${ }^{4}$ and

\section{Ali Khanehkeshi ${ }^{5}$} \\ ${ }^{1}$ Tehran Institute of Psychiatry, School of Behavioral Sciences and Mental Health, Iran University of Medical Sciences, Tehran, IR Iran \\ ${ }^{2}$ Department of Clinical Psychology, Mental Health Research Center, Tehran Institute of Psychiatry, School of Behavioral Sciences and Mental Health, Iran University of \\ Medical Sciences, Tehran, IR Iran \\ ${ }^{3}$ Faculty of Clinical Psychology, School of Behavioral Science and Mental Health, Tehran Psychiatric Institute, Metal Health Research Center, Iran University of Medical \\ Sciences, Tehran, IR Iran \\ ${ }^{4}$ Department of Art and Architecture, Payame Noor University, Tehran, IR Iran \\ ${ }^{5}$ Department of Psychology, Behbahan Branch, Islamic Azad University, Behbahan, IR Iran \\ "Corresponding author: Behrooz Birashk, Faculty of Clinical Psychology, School of Behavioral Science and Mental Health, Tehran Psychiatric Institute, Metal Health Research \\ Center, Iran University of Medical Sciences, Tehran, IR Iran, E-mail: birashk.b@iums.ac.ir
}

Received 2016 March 13; Revised 2016 April 13; Accepted 2016 April 29.

\begin{abstract}
Background: The aim of this study was to assess the prevalence of sexual dysfunction and to investigate whether there is a change in sexual dysfunction after six months of methadone maintenance therapy (MMT) compared with baseline.

Patients and Methods: We recruited 150 male Iranian patients from several centers offering methadone maintenance therapy (MMT). Patients underwent structured interview that consisted of socio-demographic characteristics, drug use, and sexual behavior, the patients completed the International Index of Erectile Function -15 (IIEF-15) and Sexual Self-efficacy Scale - Erectile Functioning (SSES-E) tests to assess sexual dysfunction. The statistical method used for analyzing data was the Mann-Whitney U test.

Results: Among men on MMT, 65\% had erectile dysfunction (ED). The baseline mean score on the IIEF was 15.55 and, after taking methadone, that positively increased to 18.12 in the post-assessment. Analysis indicated significant improvement in erectile function, sexual desire, overall satisfaction, and orgasmic function after methadone maintenance treatment. Also, the baseline means score on the SSES-E was 86.71, which increased moderately to 94.34 in the post-assessment.

Conclusions: Results showed that sexual dysfunction is a prevalent disorder in opioid-dependent males. Addiction withdrawal centers should be warned about the dysfunction caused by opioids and, from a clinical perspective, it is imperative that patients misusing opiates and those treated with methadone are routinely asked about their sexual functioning so that, if indicated, appropriate investigations and treatment can be planned. Further, the findings of this study revealed an improvement in some aspects of sexual dysfunction in patients after six months of methadone maintenance treatment. Thus, explaining to addicts that methadone causes fewer complications than using illegal drugs can help prevent premature exit from MMT.
\end{abstract}

Keywords: Sexual Dysfunctions, Opiate Dependence, Methadone

\section{Background}

Erectile dysfunction refers to men's failure to achieve or maintain full erection to the end of coitus (1). Sexual dysfunction is difficulty experienced by an individual or a couple throughout any phase of normal sexual activity, including physical pleasure, desire, preference, arousal, or orgasm (2). Sexual dysfunction can have a profound impact on a person's perceived quality of sexual life (3).

Opiate abuse has increased in prevalence in recent years throughout the world, especially in Iran $(4,5)$. Opium and its derivatives have a long history in Iranian tradition, so that pharmacological, psychotropic effects found in people with difficulties (6). Research indicates that opium was the first drug used by $46.4 \%$ of the subjects (7). Although opium use has been reported in Iran for centuries, it has evolved into a complex matter involving widespread psychosocial, familial, and economic consequences. There is no clear evidence of the actual number of drug abusers in Iran. However, some reports estimate a probable presence of two to four million people. In addition, the current, formally announced number of drug abusers in Iran is about two million $(8,9)$.

Methadone maintenance therapy (MMT) is a wellknown method of treating dependence on opioid raw materials and, in particular, is used to decrease the damage caused by these substances (10). Methadone has two enantiomeric forms: the racemic formula is used more regularly (11). MMT has been the foundation of pharmacologic management of opiate dependence (12-15). Methadone, a synthetic sedative drug used for the treatment of opium 
addiction, is also used instead of morphine and hydromorphone for patients suffering from severe pain (16).

Sexual dysfunction is a common and clinical side effect of heroin misuse and opiate-substitute treatment, because opium can cause atrophy and declining libido (17). Chronic opiate addicts experience sexual dysfunction including reduced libido and sexual performance in males and females, erectile dysfunction and delayed ejaculation in males (18), and amenorrhea and reduced fertility in females (19-24). These side-effects are often neglected and, therefore, unexplored in the routine clinical care of opiate addicts. Yet, they are highly clinically related, as they could lead to non-adherence to treatment (25).

Research indicates that heroin and methadone cause a drop in testosterone levels in males. Plasma testosterone levels have been revealed to be lower in opiate addicts, as compared with controls (26). Patients on lower doses of heroin and methadone have been found to have higher testosterone levels (27). In addition, various studies have shown the effect of heroin and methadone on testosterone levels in males. Other explanations offered to clarify opiate-induced sexual dysfunction include the a-adrenergic blocking activity of opiates, which may directly influence the functioning of accessory sex organs, and psychological factors, such as sedation, euphoria, and a chaotic lifestyle in addicts that inhibits sexual desire and performance. These patients may prefer drug-procuring behaviors to opportunities for sexual encounters $(20,28)$.

Sexual dysfunction is a common problem among addicted Iranian opiate users who undergo MMT, but only a few studies on sexual dysfunction of methadone-treated patients have been undertaken in Iran and other countries. As a result, the importance of sexual dysfunction has been underestimated. Research studies in other countries have found that up to $87 \%$ of women and $85 \%$ of men who enter MMT have reported sexual difficulty while using opium.

However, many patients with sexual dysfunction do not report this issue to clinicians and many clinicians sense discomfort among patients about dealing with sexual problems. Of the few Iranian studies conducted on sexual dysfunction, Tatari et al. (2013) (29), in their study of 157 drug-dependent subjects, found the prevalence of erectile function to be $60.5 \%$ and sexual desire to be $70.7 \%$. A study on the prevalence of erectile function among 201 Italian patients at seven methadone and buprenorphine maintenance treatment centers revealed that $24 \%$ of patients reported mild to moderate erectile dysfunction, and $18 \%$ reported severe erectile dysfunction (30).

The paucity of research on sexual dysfunction among patients on MMT in Iran and in other countries is a crucial concern. Assessment of sexual dysfunction in these patients is important, because identification and man- agement of sexual dysfunction can increase compliance with the treatment procedure, the effectiveness of which is associated with more doses and a longer duration of treatment (31). The present study is designed to examine the prevalence of sexual dysfunction and to investigate whether there is a change in sexual dysfunction following six months of MMT, compared with baseline.

Previous studies reported the prevalence and kinds of sexual dysfunction in men on MMT for opioid dependence and described factors that may contribute to sexual dysfunction. While ED is not life-threatening, it may result in withdrawal from sexual intimacy and reduced quality of life (26).

Among the side-effects of heroin misuse and opiatesubstitute treatment, sexual dysfunction is common and clinically significant. This is often ignored and, therefore, unknown in the routine clinical care of opiate addicts. Yet, it is yet highly clinically relevant, as it could lead to lack of adherence to treatment. Sexual dysfunctions noted in chronic opiate addicts include reduced libido and sexual performance in males (32), erectile dysfunction and delayed ejaculation (18), and amenorrhea and reduced fertility in females $(20,33)$.

Various assumptions have been used to explain sexual dysfunction in male opiate abusers. Cushman and Kreek (1972) (28) reported a negative correlation between high-dose methadone and low plasma testosterone levels. Apart from the effect of heroin and methadone on reducing testosterone levels in males, other causes used to explain opiate-induced sexual dysfunction include the aadrenergic blocking activity of opiates, which may directly influence the functioning of accessory sex organs.

Psychological factors, such as sedation, euphoria, and the chaotic lifestyle of addicts can impair sexual desire and performance, and these patients often prefer drugprocuring behaviors to opportunities for sexual encounters. Several studies have identified a range of sexual dysfunctions in male patients addicted to heroin and those treated with methadone (34).

\section{Objectives}

In this study, we assessed the sexual functioning of male heroin users undergoing MMT.

\section{Patients and Methods}

\subsection{Patients and Procedures}

Patients were recruited from outpatient attendees at several MMT centers between June 2015 and February 2016. Male patients aged between 25 and 50 years, with a DSM-5 
diagnosis of opiate dependence syndrome, who were dependent on heroin or were being prescribed methadone, were included in the study. Patients on methadone were required to have been using it for at least six months. The target was a sample size of 150 methadone users, and all serial attendees at the clinic were interviewed until this number was reached.

Patients were excluded from the study if they had any of the following: comorbid alcohol dependence, a chronic physical disorder, such as diabetes mellitus, hypertension, chronic pain, endocrine or urologic disorders, or rheumatoid arthritis. Participants were asked not to use antidepressants, neuroleptics, antipsychotics, sedatives, anxiolytics, or antiandrogens during the study, because of the negative effects of these medications on sexual function and the possibility of interference with the study process and goals. Participants in whom comorbidities were detected, including drug or alcohol use, severe hypertension or stress, hormonal problems due to medical or surgical conditions such as testicular surgery, or who suffered from neurological or metabolic problems or diabetes were excluded, because of the negative effects of these problems on the study procedure.

The interviews were conducted in quiet, comfortable settings. Each interview lasted approximately one hour. All eligible patients (on the basis of self-reports of drug use) were then subjected to a urinalysis for psychoactive substances to confirm their use of heroin and methadone and to exclude concurrent use of other psychoactive substances. A final number of 150 patients participated in the study.

\subsection{Interview and Administrative Tools}

A semi-structured interview was administered, which included questions on socio-demographics, drug use details, and sexual behavior. Next, the International Index of Erectile Function (IIEF-15) was administered upon admission to MMT (35).

The IIEF-15 is a reliable, multidimensional scale test that explores various aspects of sexual dysfunction (36). The test is self-administered and has 15 questions that examine 5 scales of erectile function, orgasmic function, sexual desire, intercourse satisfaction, and overall satisfaction. Maximum mean scores for the IIEF-15 are 75, and the maximum mean score for each scale is as follows: erectile function [30], orgasmic function [10], sexual desire [10], intercourse satisfaction [15], and overall satisfaction [10]. On the erectile function sub-scale, lower scores show worse erectile dysfunction, and higher scores indicate less dysfunction. The reliability and validity of IIEF-15 were standard in Iran in the study on the Farsi international index of erectile dysfunction and doppler ultrasonography, which evaluated male impotence (37).

The sexual self-efficacy scale-erectile functioning(SSESE) is a short self-report measure of the cognitive aspect of erectile functioning and adjustment in men. It evaluates a man's attitudes about his sexual and erectile competence in a variety of conditions. The scale may be fulfilled by a man to obtain self-ratings or by his partner to obtain verification. Self-efficacy refers to confidence in the belief that one can perform a certain task or behave adequately in a given situation (38). Sexual self-efficacy is of great concern to most men and a topic of increasing interest within an aging population.

The SSES-E yields a self-efficacy strength score obtained by summing the values in the Confidence column and dividing by 25 (the number of activities rated). Any activity not checked in the Can Do column is presumed to have a 0 confidence (i.e., strength) rating. Some are reluctant to use the 10-point interval, so any continuous number recorded may be used in the Confidence column. Higher scores indicate greater confidence in the man's erectile competence (39).

\subsection{Statistical Analysis}

The statistical method used to analyze the data was the Mann-Whitney U test to reveal the changes that participants reported in their SD at admission to MMT (baseline), compared with six months of methadone treatment (postassessment).

\section{Results}

The study included 150 married males who were between 25 and 50 years old (mean: 35.48 ; SD $=7.91$ ). The majority of participants was employed and had education levels of diploma ( $\mathrm{n}=68 ; 45.3 \%$ ) or bachelor's degree ( $\mathrm{n}$ $=50 ; 33.3 \%$ ). Participants were on methadone, with the dose gradually increasing. Results showed that age, education, employment, and methadone treatment duration were not associated with sexual dysfunction prevalence (P $>0.05$ ).

The baseline erectile dysfunction mean score on the IIEF was 15.55, which showed a moderate prevalence for erectile dysfunction among participants after taking methadone that positively increased to 18.12 in the postassessment. Further analysis showed that the baseline orgasmic function score was 5.42, which increased moderately to 6.98 in the post-assessment (Table 2). The baseline sexual desire score was 4.66 , which increased moderately to 5.90 in the post-assessment. Further analysis revealed a slight improvement in sexual desire among par- 
Table 1. General Characteristics of the Methadone Study Patients

\begin{tabular}{|c|c|c|c|}
\hline Variables & $\mathbf{N}$ & Mean \pm SD & $\begin{array}{c}\text { Frequency } \\
(\%)\end{array}$ \\
\hline \multicolumn{4}{|l|}{ Age } \\
\hline $25-30$ & 54 & \multirow{3}{*}{$35.48 \pm 7.91$} & 36 \\
\hline $31-40$ & 55 & & 36.66 \\
\hline $41-50$ & 41 & & 27.33 \\
\hline \multicolumn{4}{|l|}{ Occupation } \\
\hline Employed & 101 & & 67.3 \\
\hline Unemployed & 49 & & 32.7 \\
\hline \multicolumn{4}{|l|}{ Education } \\
\hline Secondary School & 34 & & 16 \\
\hline Diploma & 68 & & 45.3 \\
\hline Bachelor's & 50 & & 33.3 \\
\hline Post Graduate & 8 & & 5.3 \\
\hline \multicolumn{4}{|l|}{ Marital status } \\
\hline Married & 83 & & 55.3 \\
\hline Single & 67 & & 44.7 \\
\hline \multicolumn{4}{|l|}{ History of Drug Use } \\
\hline $\begin{array}{l}\text { Age of First Opioid } \\
\text { Use }\end{array}$ & & $19.28 \pm 3.53$ & \\
\hline $\begin{array}{l}\text { Duration of } \\
\text { Addiction }\end{array}$ & & $16.19 \pm 8.80$ & \\
\hline $\begin{array}{l}\text { Duration of } \\
\text { Methadone } \\
\text { Treatment } \\
\text { (Month) }\end{array}$ & & $3.28 \pm 1.17$ & \\
\hline
\end{tabular}

ticipants after taking methadone, compared with baseline (Table 2). The baseline overall satisfaction score was 4.79 , which increased moderately to 5.85 in the postassessment. The baseline erectile functioning (SSES-E) score was 86.71 , which increased moderately to 94.34 in the post-assessment. Further analysis revealed overall sexual satisfaction and erectile functioning (SSES-E) among participants slightly improved after taking methadone, compared with baseline.

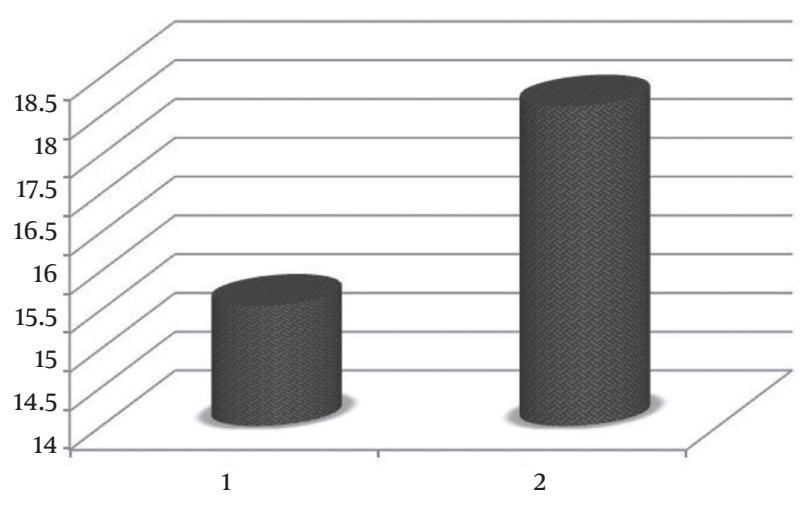

Figure 1. Erectile Function Before and After MMT

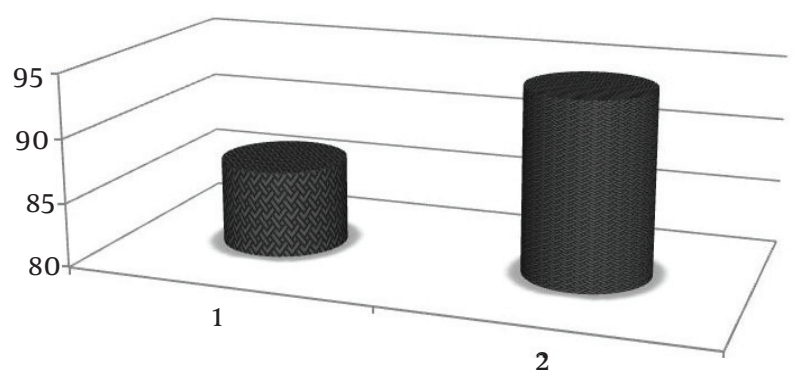

Figure 2. Sexual Self-Efficacy (SSE) Before and After MMT

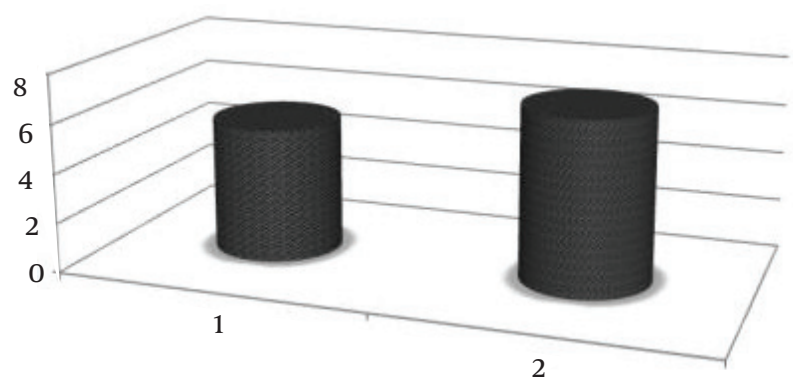

Figure 3. Orgasmic Function Before and After MMT

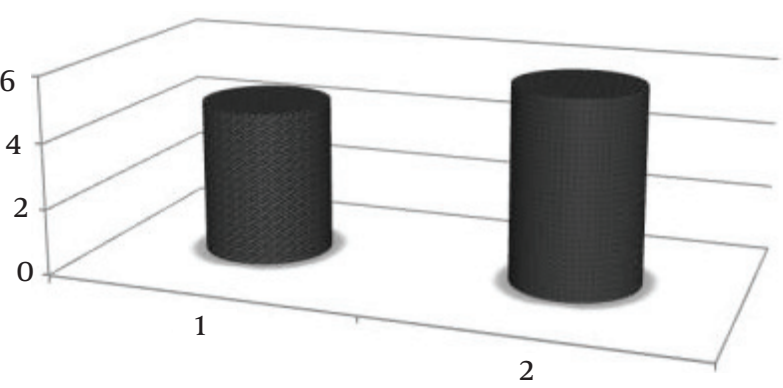

Figure 4. Sexual Desire Before and After MMT

\section{Discussion}

This study showed that erectile dysfunction and other sexual dysfunctions have a very high prevalence in opioiddependent males. Among men on MMT, 65\% had erectile dysfunction (ED) and $27 \%$ had moderate to severe ED, $72.66 \%$ of whom were men younger than 40 and $27.34 \%$ of whom were aged $40+$. The frequency of erectile dysfunction in the overall population is about $16.1 \%(40,41)$.

One of the reasons for non-adherence to treatment with agonists useful in MMT relates to concerns about its sexual side-effects. We have found that sexual dysfunc- 
Table 2. IIEF Scores of Erectile Dysfunction and Related Sexual Aspects in Baseline and After Six Months of Maintenance Treatment (MMT) $(\mathrm{n}=150)$

\begin{tabular}{|c|c|c|c|c|c|}
\hline Variable & Pre-Assessment, Mean \pm SD & Post-Assessment, Mean \pm SD & $\mathbf{U}$ & $\mathbf{Z}$ & P Value \\
\hline Erectile function & $15.55 \pm 2.08$ & $18.12 \pm 2.06$ & 289.000 & 2.44 & 0.009 \\
\hline Orgasmic function & $5.42 \pm 3.89$ & $6.98 \pm 2.67$ & 263.000 & 3.57 & 0.015 \\
\hline Sexual desire & $4.66 \pm 3.12$ & $5.90 \pm 2.40$ & 245.000 & 2.39 & 0.017 \\
\hline Overall satisfaction & $4.79 \pm 2.76$ & $5.85 \pm 3.22$ & 236.000 & 3.17 & 0.001 \\
\hline Sexual self-efficacy (SSE) & $86.71 \pm 10.09$ & $94.34 \pm 10.50$ & 267.000 & 2.50 & 0.009 \\
\hline
\end{tabular}

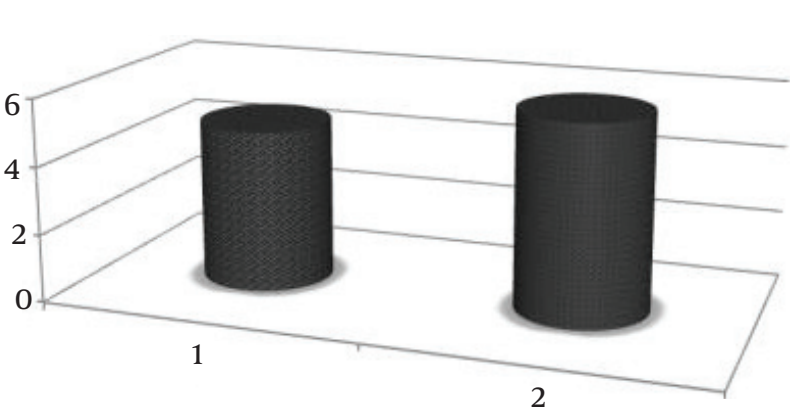

Figure 5. Overall Satisfaction Before and After MMT

tion is a common problem among opiate-dependent patients who are referred for treatment $(30,42)$. In the current study, the severity of some aspects of sexual dysfunction among participants decreased moderately after six months of extensive methadone treatment. Results indicated that orgasmic dysfunction was moderately prevalent. The research of Palha and Esteves (2002) (43, 44), who studied sexual dysfunction among 101 heroin addicts, found that $60 \%$ of men in their study had problems achieving orgasm. They also found that $75 \%$ of men in their study complained of low libido, 71\% reported altered sexual arousal, and $72 \%$ had reduced sexual satisfaction. Additional treatment, such as androgen replacement therapy, might be necessary. In addition, these difficulties might have been the result of a variety of psychological and interpersonal factors not reported by participants.

Drug addiction is a nearly universal problem and crisis. This phenomenon has crossed geographical borders and destroyed many lives (45). Some scholars believe that addiction is the result of urban development, such as in the first and third regions in central Isfahan city (46). Public participation plays an important role in reducing this problem $(23,47,48)$. Within Isfahan city, there are three urban social factors that can help reduce drug addiction (49): urban spirit assessment and its value to the city center (50), artistic and musical activities and creating a happy environment (51), and encouraging youth to know the history and traditions of their country and to feel proud of their culture (52).

\subsection{Conclusion}

In the present study, sexual problems slightly improved after participants took methadone. The long-term side-effects of opioid dependence on decreased libido were likely to be related to the core features of sexual desire and overall satisfaction. These possibly required additional therapies or could have been attributable to the disrupted affective and sexual relationship of participants with their spouses, requiring psycho-intervention, sex therapy, or marital therapy.

Several limitations existed in this study. This was crosssectional research, without a control group, hormone assay, or monthly evaluation by IIEF-15. We used baseline sexual status to compare with post-assessment results of sexual function among participants. It was methadone use and improvement in sexual dysfunction from our observations in this pilot study. Additional studies with larger samples and lower dropout rates are necessary. Furthermore, our data was based on self-reporting, which lacked objective evidence. However, we administered the IIEF-15, which is recognized as the gold standard for evaluating sexual dysfunction (53). We evaluated sexual dysfunction at an appropriate time, in the sixth month, when our extensive interviews with patients showed they frequently reported having adjusted to both the methadone dose and treatment conditions in the MMT program.

The present study found no relationship between demographics, drug use history, and duration of MMT to improvement in sexual dysfunction. Nevertheless, a higher methadone dose and longer duration of MMT, in comparison with a low dose and shorter treatment duration in experimental and control groups, are subjects for future studies on sexual dysfunction in male patients, particularly given that some well-known studies have claimed the reverse effects of methadone treatment on certain aspects of sexual function, such as libido and orgasmic function (26). 
Sexual dysfunction is an important concern for many patients undergoing MMT, and a good opiate use treatment program must address this issue. Androgen replacement (54) and pharmacological treatment may be effective approaches for these patients, while psycho-intervention for patients and counseling programs for couples may be useful (55-57).

This study showed that erectile dysfunction and other sexual dysfunctions have a very high prevalence in opioiddependent males. This subject has drawn insufficient attention and is still unknown as a public health issue. In turn, this problem has its own effects on patients' health and damages the prognosis for recovery from drug abuse. Moreover, addiction withdrawal centers are linked to this facet of patients' health. Therefore, they should be forewarned about the side-effects and dysfunctions caused by opioids. In addition, explaining to addicts that methadone causes fewer complications than using illegal drugs can help prevent premature exit from MMT. Moreover, this matter should be recognized as a means of preventing addiction in the future.

\section{Footnote}

Funding/Support: The present study was financially supported by the Iran University of Medical Sciences, Tehran, with research project code 94-01-25626.

\section{References}

1. Ricci E, Parazzini F, Mirone V, Imbimbo C, Palmieri A, Bortolotti A, et al. Current drug use as risk factor for erectile dysfunction: results from an Italian epidemiological study. Int J Impot Res. 2003;15(3):221-4. doi: 10.1038/sj.ijir.3901008. [PubMed: 12904809].

2. Watkins ER, Nolen-Hoeksema S. A habit-goal framework of depressive rumination. J Abnorm Psychol. 2014;123(1):24-34. doi: 10.1037/a0035540. [PubMed: 24661156].

3. Eden KJ, Wylie KR. Quality of sexual life and menopause. Womens Health (Lond). 2009;5(4):385-96. doi: 10.2217/whe.09.24. [PubMed: 19586430].

4. Saberi Zafarghandi M, Rahimi-Movaghar A, Amin-Esmaeili M, Razaghi E, Khastoo G, Jar-Siah R. Situation of Drug Use, Addiction and Related Services in the Laborers of Assaluyeh Industrial Area (South Pars Gas Field) in 2007. Hakim Res J. 2010;12(4):58-68.

5. Saberi Zafarghandi MB, Jadidi M. Drug Dependency and Women's Health. Women's Health Bulletin. 2014 November;2(1):e22191. doi: 10.17795/whb-22191.

6. Saberi Zafarghandi M, Tabasi Y, Bolhari J, Baghbanian A, Yazdani S, Adibfar M. The Iintegration program of Prevention and Treatments of Substance Use and HIV/AIDS in the Rural Primary Health Care (PHC) System of Iran. Int J High Risk Behav Addict. 2016;In Press(In Press):e29173. doi: 10.5812/ijhrba.29173.

7. Eskandarieh S, Nikfarjam A, Tarjoman T, Nasehi A, Jafari F, SaberiZafarghandi MB. Descriptive Aspects of Injection Drug Users in Iran's National Harm Reduction Program by Methadone Maintenance Treatment. Iran J Public Health. 2013;42(6):588-93. [PubMed: 23967426].
8. Saberi Zafarghandi MB, Jadidi M, Khalili N. Iran's Activities on Prevention, Treatment and Harm Reduction of Drug Abuse. Int J High Risk Behav Addict. 2015;4(4):22863. doi: 10.5812/ijhrba.22863. [PubMed: 26870709].

9. Saberi Zafarghandi MB, Roshanpajouh M, Mirkazemi R, Bolhari J. Challenges of Integrating the Drug Demand Reduction into Primary Health Care Services Program in Iran: Report of a Roundtable. Iran $J$ Psychiatr Clin Psychol. 2014;9(4):326-9.

10. Hoseiny H, Jadidi M, Habiballah Nataj L, Saberi-Zafarghandi MB. The effect of methadone-maintenance therapy with and without interactive treatment on improving emotion-regulation strategies and resilience among opiate-dependent clients. Int J High Risk Behav Addict. 2015;4(1):23526. doi: 10.5812/ijhrba.23526. [PubMed: 25821751].

11. Inturrisi CE. Pharmacology of methadone and its isomers. Minerva Anestesiol. 2005;71(7-8):435-7. [PubMed: 16012416].

12. Ahmadi J. Methadone versus buprenorphine maintenance for the treatment of heroin-dependent outpatients.J Substance Abuse Treatment. 2003;24(3):217-20. doi: 10.1016/S0740-5472(03)00024-2.

13. Barnett PG, Rodgers JH, Bloch DA. A meta-analysis comparing buprenorphine to methadone for treatment of opiate dependence. Addiction. 2001;96(5):683-90. doi: 10.1080/09652140020039053. [PubMed: 11331027].

14. Rahimi-Movahgar A, Khastoo G, Razzaghi E, Saberi-Zafarghandi M, Noroozi A, Jar-Siah R. Compulsory methadone maintenance treatment of severe cases of drug addiction in a residential setting in Tehran, Iran: outcome evaluation in two and six-month follow-up. Payesh Health Monitor. 2011;10(4):505-14.

15. Saberi Zafarghandi M. Some of the Challenges of Mental Health and Addiction in Iran. Iran J Psychiatr Clin Psychol. 2011;17(2):161-57.

16. Bruera E, Palmer JL, Bosnjak S, Rico MA, Moyano J, Sweeney C, et al. Methadone versus morphine as a first-line strong opioid for cancer pain: a randomized, double-blind study. J Clin Oncol. 2004;22(1):18592. doi: $10.1200 / J C O .2004 .03 .172$. [PubMed: 14701781$]$.

17. Daniell HW. Hypogonadism in men consuming sustained-action oral opioids. J Pain. 2002;3(5):377-84. [PubMed: 14622741].

18. Mirin SM, Meyer RE, Mendelson JH, Ellingboe J. Opiate use and sexual function. Am J Psychiatry. 1980;137(8):909-15. doi:10.1176/ajp.137.8.909. [PubMed: 6774622].

19. Mathis JL. Sexual Aspects of Heroin Addiction. Med Aspects Hum Sexuality. 1970;4(9):98-109.

20. Mousavi Nik M, Zafarghandi S, Birashk B, Assari A. Evaluating quality of well-being, marital adjustment and sexual dysfunction between infertile women. Iran J Reproduct Med. 2015.

21. Mousavinik M. Effect of rational emotive behavior therapy on depression in infertile women. ZENITH Int J Multidisciplinary Res. 2012;2(10):77-84.

22. Mousavi Nik M, Basavarajappa K, Khaneh Keshi A. . Effect of motivational interviewing and rational emotive behavior therapy (REBT) for substance use disorders. J Addict Res Ther. 2014;5(3):121.

23. Mousavi Nik M, Assari A, Khaneh Keshi A, Eshaghi Farahmand R. Effect of Rational Emotive Behavior Therapy (REBT) on Anxiety and Irrational Beliefs among Infertile Women. Nourosci J Shefaye Khatam. 2014;2(3):56.

24. Mousavi Nik M. Rational emotive behavior therapy (REBT) for depression and smoking cessation in infertile women. J Addict Res Ther. 2013;4(4):114.

25. Al-Gommer O, George S, Haque S, Moselhy H, Saravanappa T. Sexual dysfunctions in male opiate users: a comparative study of heroin, methadone, and buprenorphine. Addict Disord Their Treatment. 2007;6(3):137-43. doi:10.1097/ADT.0b013e31802b4e8c.

26. Brown R, Balousek S, Mundt M, Fleming M. Methadone maintenance and male sexual dysfunction. J Addict Dis. 2005;24(2):91-106. doi: 10.1300/J069v24n02_08. [PubMed: 15784526].

27. Cushman P. Plasma testosterone in narcotic addiction. Am J Med. 1973;55(3):452-8. [PubMed: 4743346]. 
28. Cicero TJ, Bell RD, Wiest WG, Allison JH, Polakoski K, Robins E. Function of the male sex organs in heroin and methadone users. $N$ Engl J Med. 1975;292(17):882-7. doi: 10.1056/NEJM197504242921703. [PubMed: 1117911].

29. Tatari F, Shakeri J, Farnia V, Heidari F, Rezaei M. Bupropion in methadone induced erectile dysfunction. Life Sci J. 2013;10(9).

30. Quaglio G, Lugoboni F, Pattaro C, Melara B, Mezzelani P, et al. Erectile dysfunction in male heroin users, receiving methadone and buprenorphine maintenance treatment. Drug Alcohol Depend. 2008;94(1-3):12-8. doi: 10.1016/j.drugalcdep.2007.09.025. [PubMed: 18083312].

31. Strain EC, Bigelow GE, Liebson IA, Stitzer ML. Moderate- vs high-dose methadone in the treatment of opioid dependence: a randomized trial. JAMA. 1999;281(11):1000-5. [PubMed:10086434].

32. Cushman P. Sexual behavior in heroin addiction and methadone maintenance. Correlation with plasma luteinizing hormone. NYState J Med. 1972;72(11):1261-5. [PubMed: 4503902].

33. Mousavi Nik M. The Implicate of Irrational Beliefs in Depression among Infertile Women. J Am Sci. 2012;8(8):853-7.

34. Maremmani I, Pani PP, Pacini M, Perugi G. Substance use and quality of life over 12 months among buprenorphine maintenance-treated and methadone maintenance-treated heroin-addicted patients. $J$ Subst Abuse Treat. 2007;33(1):91-8. doi: 10.1016/j.jsat.2006.11.009. [PubMed: 17588494].

35. Rosen RC, Riley A, Wagner G, Osterloh IH, Kirkpatrick J, Mishra A. The international index of erectile function (IIEF): a multidimensional scale for assessment of erectile dysfunction. Urol. 1997;49(6):822-30. doi:10.1016/S0090-4295(97)00238-0.

36. Gonzáles AI, Sties SW, Wittkopf PG, de Mara LS, Ulbrich AZ, Cardoso FL. Validation of the International Index of Erectile Function (IIFE) for Use in Brazil. Arquivos Brasileiros De Cardiologia. 2013;101(2):176. doi: 10.5935/abc.20130141.

37. Mehraban D, Shabaninia S, Nader IG, Esfahani F. Farsi international index of erectile dysfunction and doppler ultrasonography in the evaluation of male impotence. Iran J Surg. 2006;14(1):25-31.

38. Bandura A. Self-efficacy mechanism in human agency. Am Psychol. 1982;37(2):122. doi: 10.1037/0003-066X.37.2.122.

39. Fichten C, Spector I, Amsel R, Creti L, Brender W, Libman E. Sexual selfefficacy scale-erectile functioning. ; 1998.

40. Mirone V, Imbimbo C, Bortolotti A, Di Cintio E, Colli E, Landoni M. Cigarette smoking as risk factor for erectile dysfunction: results from an Italian epidemiological study. European Urol. 2002;41(3):294. doi: 10.1016/S0302-2838(02)00005-2.

41. Nicolosi A, Laumann EO, Glasser DB, Moreira ED, Paik A, Gingell C, et al. Sexual behavior and sexual dysfunctions after age 40: the global study of sexual attitudes and behaviors. Urology. 2004;64(5):991-7. doi:10.1016/j.urology.2004.06.055. [PubMed: 15533492].

42. Hallinan R, Byrne A, Agho K, McMahon C, Tynan P, Attia J. Erectile dysfunction in men receiving methadone and buprenorphine maintenance treatment. J Sex Med. 2008;5(3):684-92. doi: 10.1111/j.17436109.2007.00702.x. [PubMed: 18093096].

43. Palha AP, Esteves M. A study of the sexuality of opiate addicts. J Sex Marital Ther. 2002;28(5):427-37. [PubMed: 12378844].

44. Babakhanian M, Alam Mehrjerdi Z, Shenaiy Y. Sexual dysfunction in male crystalline heroin dependents before and after MMT: a pilot study. Arch Iran Med. 2012;15(12):751-5. [PubMed: 23199246].

45. Assari A, Mahesh T. Demographic comparative in heritage texture of Isfahan city. J Geography and Regional Planning. 2011;4(8):463.

46. Assari A, Mahesh T, Assari E. Conservation of historic urban core in traditional Islamic culture: case study of Isfahan city. Indian J SciTechnol. 2012;5(1):1970-6.

47. Assari A, Mahesh T, Assari E. Role of public participation in sustainability of historical city: usage of TOPSIS method. Indian J Sci Technol. 2012;5(3):2289-94

48. Mousavi Nik M, Saberi Zafarghandi MB, Birashk B, Assari A, Eshaghi Farahmand R. Identifying and Reducing Occupational Road Safety Risks. Neurosci J Shefaye Khatam. 2015;2.

49. Assari A. Planning for conservation of heritage area of Isfahan city in Iran. University of Mysore; 2015.

50. Assari A, Assari E. Urban spirit and heritage conservation problems: case study Isfahan city in Iran. J Am Sci. 2012;8(1):202-109.

51. Assari A, Maheh TM, Assari E. Investigating Sustainability of Bazaars Iniranian Historical Cities. United Kingdom: Cambridge Scholars Publishing; 2015.

52. Assari A, Mahesh T, Emtehani M, Assari E. Comparative sustainability of bazaar in Iranian traditional cities: Case studies in Isfahan and Tabriz. Int J on Technical and Physical Problems of Engineering. 2011(9):1824.

53. Rosen RC, Althof SE, Giuliano F. Research instruments for the diagnosis and treatment of patients with erectile dysfunction. Urology. 2006;68(3 Suppl):6-16. doi: 10.1016/j.urology.2006.05.046. [PubMed: 17011371].

54. Daniell HW. Sex hormone deficiency in depressed patients receiving opioids. Arch Intern Med. 2004;164(7):804. doi: 10.1001/archinte.164.7.804-a. [PubMed: 15078652].

55. Nurnberg HG, Hensley PL, Gelenberg AJ, Fava M, Lauriello I, Paine S. Treatment of antidepressant-associated sexual dysfunction with sildenafil: a randomized controlled trial. JAMA. 2003;289(1):56-64. [PubMed: 12503977].

56. Vaziri S, Mousavinik M. The Relation between Meta Worry and Meta Cognition Beliefs with Phobia.Andisheh Va Raftar (Applied Psychology). 2009;3(10):59-70.

57. Assari A, Birashk B, Mousavinik M, Naghdbishi R. Impact of Built Environment on Mental Health: Review of Tehran City In Iran. Int J"Technical and Physical Problems of Engineering. 2016;8(26):81-7. 